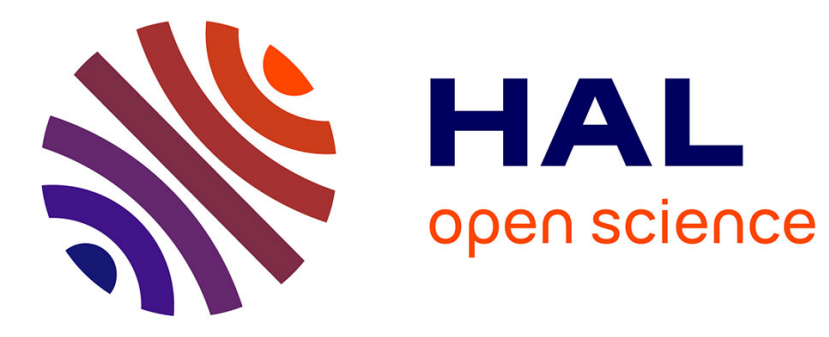

\title{
Metallic $\mathrm{Mg}$ insertion in rf deposited $\mathrm{MgO}$ barrier M. M. C. Souzaa, R. C. Sousa, C. Ducruet, S. Auffret, B. Dieny
}

\section{To cite this version:}

M. M. C. Souzaa, R. C. Sousa, C. Ducruet, S. Auffret, B. Dieny. Metallic Mg insertion in rf deposited MgO barrier. Journal of Applied Physics, 2010, 107, pp.09C702. 10.1063/1.3355995 . cea-02886853

\section{HAL Id: cea-02886853 https://hal-cea.archives-ouvertes.fr/cea-02886853}

Submitted on 1 Jul 2020

HAL is a multi-disciplinary open access archive for the deposit and dissemination of scientific research documents, whether they are published or not. The documents may come from teaching and research institutions in France or abroad, or from public or private research centers.
L'archive ouverte pluridisciplinaire HAL, est destinée au dépôt et à la diffusion de documents scientifiques de niveau recherche, publiés ou non, émanant des établissements d'enseignement et de recherche français ou étrangers, des laboratoires publics ou privés. 


\section{Metallic Mg insertion in rf deposited MgO barrier}

Cite as: J. Appl. Phys. 107, 09 C702 (2010); https://doi.org/10.1063/1.3355995

Submitted: 03 November 2009. Accepted: 05 December 2009. Published Online: 20 April 2010

M. M. C. Souza, R. C. Sousa, C. Ducruet, S. Auffret, and B. Dieny

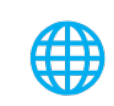

\section{ARTICLES YOU MAY BE INTERESTED IN}

Tunnel magnetoresistance of $604 \%$ at $300 \mathrm{~K}$ by suppression of Ta diffusion in $\mathrm{CoFe} B / \mathrm{MgO} / \mathrm{CoFe} B$ pseudo-spin-valves annealed at high temperature

Applied Physics Letters 93, 082508 (2008); https://doi.org/10.1063/1.2976435

230\% room-temperature magnetoresistance in $\mathrm{CoFeB} / \mathrm{MgO} / \mathrm{CoFeB}$ magnetic tunnel junctions Applied Physics Letters 86, 092502 (2005); https://doi.org/10.1063/1.1871344

Perpendicular-anisotropy CoFeB-MgO magnetic tunnel junctions with a MgO/CoFeB/Ta/ CoFeB/MgO recording structure

Applied Physics Letters 101, 022414 (2012); https://doi.org/10.1063/1.4736727

\section{Lock-in Amplifiers up to $600 \mathrm{MHz}$

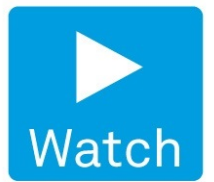

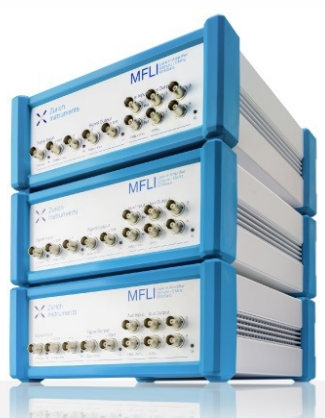

J. Appl. Phys. 107, 09 C702 (2010); https://doi.org/10.1063/1.3355995

107, $09 C 702$

(C) 2010 American Institute of Physics. 


\title{
Metallic Mg insertion in rf deposited MgO barrier
}

\author{
M. M. C. Souza, ${ }^{\text {a) }}$ R. C. Sousa, C. Ducruet, S. Auffret, and B. Dieny \\ SPINTEC (UMR 8191 CEA-CNRS-UJF), CEA/INAC, 38054 Grenoble Cedex, France
}

(Presented 21 January 2010; received 3 November 2009; accepted 5 December 2009; published online 20 April 2010)

\begin{abstract}
Metallic $\mathrm{Mg}$ insertions in $\mathrm{rf}$ deposited $\mathrm{MgO}$ barrier of magnetic tunnel junctions structures were investigated in a resistance-area (RA) range from 1 to $1000 \Omega \mu \mathrm{m}^{2}$. For the first time, investigations on $\mathrm{Mg}$ insertions above the $\mathrm{MgO}$ barrier and simultaneously on both sides of the barrier are reported. It is shown that for RA larger than $5 \Omega \mu \mathrm{m}^{2}$, a bottom $\mathrm{Mg}$ insertion does not improve the tunnel magnetoresistance (TMR) ratio compared to a sample with no $\mathrm{Mg}$ insertion. Furthermore, a top $\mathrm{Mg}$ insertion yields a lower TMR ratio decreasing as the Mg thickness is increased. On the other side, for RA lower than $5 \Omega \mu \mathrm{m}^{2}$, there is no significant difference between top and bottom $\mathrm{Mg}$ insertions indicating that in this region, the $\mathrm{MgO}$ crystallization occurs mainly during the annealing process. In the RA range investigated, there is no significant difference in coupling field for different insertions. In very low RA regions between 1 and $10 \Omega \mu \mathrm{m}^{2}$, an increase in TMR is observed for $0.3 \mathrm{~nm}$ insertions simultaneously below an above the barrier. (C) 2010 American Institute of Physics. [doi:10.1063/1.3355995]
\end{abstract}

\section{INTRODUCTION}

Magnetic tunnel junctions (MTJ) are the core elements of magnetic random access memories (MRAM) and considered for other spintronic devices because of their tunable resistance range and large magnetoresistance amplitude. Studies on $\mathrm{MgO}$ barriers have been encouraged since the publication of a series of theoretical calculations that predicted an extremely high TMR above $1000 \%$ in MTJ with crystalline $\mathrm{MgO}$ barrier. ${ }^{1,2}$ The use of such barriers in tunnel junction devices for magnetic read heads which have resistances of about $50 \Omega$ requires target values of resistancearea (RA) product below $1 \Omega \mu \mathrm{m}^{2}$. Besides, in spin transfer torque MRAM, there is a need to reduce RA level below $10 \Omega \mu \mathrm{m}^{2}$ to reduce the write voltage well below the barrier breakdown voltage. Recently, several results demonstrated that the insertion of a thin $\mathrm{Mg}$ layer deposited on the bottom ferromagnetic electrode prior to the $\mathrm{MgO}$ barrier deposition enhances the TMR signal in the low RA value range. ${ }^{3,4}$ The $\mathrm{Mg}$ insertion also allows decreasing the RA product by reducing the barrier height or the effective thickness of the $\mathrm{MgO}$ barrier. Some studies concluded that this improvement is due to the reduction of initially oxidized interface, while others claimed that it is due to the improvement in the $\mathrm{MgO}$ texture. Up to now the physical influence of $\mathrm{Mg}$ insertion on RA and TMR amplitude is not yet clear. This work further investigates the effect of metallic $\mathrm{Mg}$ insertion below and above $\mathrm{MgO}$ barriers, and simultaneously on both sides of the barrier. The TMR signal dependence on the metallic $\mathrm{Mg}$ thickness was studied in the RA range from 1 to $1000 \Omega \mu \mathrm{m}^{2}$.

\section{EXPERIMENTS}

The magnetic stack consists of seed layer/Ta $3 / \mathrm{CoFeB}$ 4/Mg insert/ $\mathrm{MgO}_{x} / \mathrm{Mg}$ insert/CoFeB 3/Ru 1.8/Co 2/IrMn

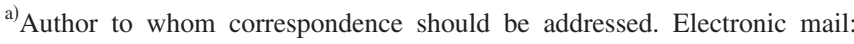
maria.marins-de-castro-souza@cea.fr.
}

7/capping layer (thickness in nanometers). The $\mathrm{Mg}$ insertion thickness was varied between 0 and $0.5 \mathrm{~nm}$ for the top and bottom insertions. The free layer consists in $\mathrm{CoFeB}$ and pinned layer is a synthetic antiferromagnet exchanged biased by an $\mathrm{IrMn}$ layer. The seed and capping layers are Ta $3 / \mathrm{CuN}$ 60/Ta 5/Ru 7 and Ta 5/Ru 7, respectively. The magnetic stack was deposited on a $100 \mathrm{~mm}$ diameter thermally oxidized $\mathrm{Si}$ wafer. The metallic layers were prepared by dc sputtering at an Ar pressure of $2.3 \times 10^{-3}$ mbar and room temperature. The $\mathrm{MgO}$ barrier was deposited by rf sputtering from an $\mathrm{MgO}$ target in an off-axis configuration. With this wafertarget configuration, a $\mathrm{MgO}$ thickness gradient is obtained. The $\mathrm{MgO}$ wedge thickness is calculated from the Kiessig fringes measured by $\mathrm{x}$-ray diffraction. Using this off-axis deposition (wafer center offset by $100 \mathrm{~mm}$ from the target center), a $\mathrm{MgO}$ wedge varying from 0.7 to $1.8 \mathrm{~nm}$ across the wafer is obtained for our given deposition time. For the same deposition time, when the substrate is facing the target, the corresponding $\mathrm{MgO}$ thickness is $2.2 \mathrm{~nm}$. Profile calibration measurements show that this offset condition produces a quasilinear thickness profile across the wafer. Very similar profile was also observed for others materials ( $\mathrm{Mg}$ and $\mathrm{Al})$ in our deposition tool. The annealing temperature was optimized in a range from 270 to $370{ }^{\circ} \mathrm{C}$, with the highest TMR ratio being obtained at about $340{ }^{\circ} \mathrm{C}$. The samples were subsequently annealed under vacuum at $340{ }^{\circ} \mathrm{C}$ for $2 \mathrm{~h}$ under a magnetic field of $2.3 \mathrm{kOe}$ at low $10^{-5}$ mbar base pressure. The TMR ratio and the RA product were obtained from a current-in-plane (CIP) measurement on unpatterned wafers. ${ }^{5}$ Magnetic characterizations were made using a vibrating sample magnetometer (VSM).

\section{RESULTS}

TMR ratio is plotted as a function of RA product in Fig. 1. In this graph, we can define two distinct regions: RA larger than $5 \Omega \mu \mathrm{m}^{2}$ and smaller than this value. For RA 


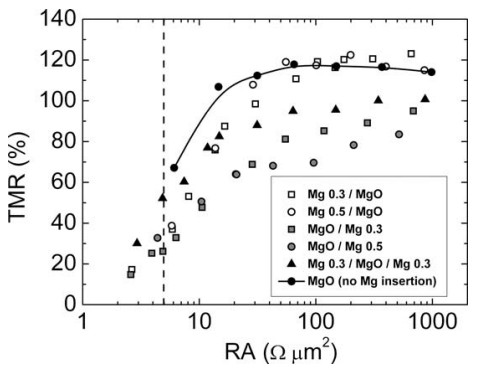

FIG. 1. Dependence of the TMR ratio on the RA product for different $\mathrm{Mg}$ insertions. The behavior of samples is analyzed in two different regions defined by the dashed line: RA smaller and greater than $5 \Omega \mu \mathrm{m}^{2}$.

values larger than $5 \Omega \mu \mathrm{m}^{2}$, the $\mathrm{Mg}$ insertion below or above the $\mathrm{MgO}$ barrier does not improve the TMR ratio compared to the sample without $\mathrm{Mg}$ insertion. This is similar to what had been previously observed for bottom $\mathrm{Mg}$ insertions. Comparing the two types of insertions, we observed that the top insertion results in a lower TMR value compared to the bottom insertion and no-insertion samples. At high RA values, TMR signal drops as the $\mathrm{Mg}$ is increased from 0.3 to $0.5 \mathrm{~nm}$. In RA region lower than $5 \Omega \mu \mathrm{m}^{2}$, no significant difference in TMR is observed between top and bottom insertions. The reason which has been put forward to explain the increase in TMR observed at low RA levels in bottom metallic $\mathrm{Mg}$ insertions is an improvement in the $\mathrm{MgO}(001)$ crystal orientation upon annealing. It is striking that the same effect seems to occur when the $\mathrm{Mg}$ insertion is introduced after the $\mathrm{MgO}$ barrier deposition. This is due to the fact that the crystallization of $\mathrm{MgO}$ and $\mathrm{CoFeB}$ mainly occurs during the annealing process. As a result, the positioning of the $\mathrm{Mg}$ insertion above or below the $\mathrm{MgO}$ barrier does not matter so much since in both cases the $\mathrm{Mg}$ insertion at the $\mathrm{MgO} /$ $\mathrm{CoFeB}$ interface equivalently affects the $\mathrm{CoFeB}$ and $\mathrm{MgO}$ crystallization. Improvements from the $\mathrm{Mg}$ insertions are especially clear in the RA product region below $10 \Omega \mu \mathrm{m}^{2}$, which is also the most relevant for applications requiring large current density. In this region, TMR and RA levels for a no-insertion sample could not be evaluated since no CIP measurement was possible because the free and pinned layers become increasingly coupled. Therefore RA values below $5 \Omega \mu \mathrm{m}^{2}$ can only be obtained by introducing an $\mathrm{Mg}$ insertion. Since the effect is most noticeable in the very thin barrier range, improved tunnel barrier continuity and pinhole suppression might also be playing a role in the observed TMR improvement. The highest TMR signal observed for RA values between 1 and $10 \Omega \mu \mathrm{m}^{2}$ was obtained in samples having simultaneously $0.3 \mathrm{~nm} \mathrm{Mg}$ insertions below and above the $\mathrm{MgO}$ barrier, showing 50\% TMR and an RA of about $4.8 \Omega \mu \mathrm{m}^{2}$. High-resolution TEM images are being carried out to compare the barrier quality and conformity in the low RA range.

The RA product is plotted in Fig. 2 as a function of the $\mathrm{MgO}$ thickness for different $0.3 \mathrm{~nm} \mathrm{Mg}$ insertions. The RA increases exponentially as a function of the barrier thickness as expected from tunneling. For RA levels below $10 \Omega \mu \mathrm{m}^{2}$, experimental points slightly deviate from the exponential behavior for both bottom and top $\mathrm{Mg}$ insertions. This can be explained assuming an increase in the barrier pinhole density

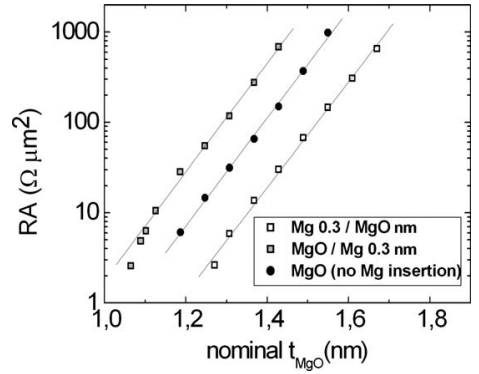

FIG. 2. RA product as a function of the as deposited $\mathrm{MgO}$ thickness for different $0.3 \mathrm{Mg}$ insertions.

in the barrier, resulting in an increasing fraction of metallic conduction as opposed to the electron tunneling through the barrier.

At same nominal thickness of $\mathrm{MgO}$, a bottom insertion presents an RA level lower compared to a no-insertion sample while a top insertion shows a RA level greater than the sample without $\mathrm{Mg}$. In order to explain this fact, let us consider the schematic from Fig. 3. Near the interface, some of the oxygen from the $\mathrm{MgO}$ layer migrates to the $\mathrm{Mg}$ layer. The region of oxygen diffusion contains lot of oxygen vacancies and is poorly insulating. Consequently, we can consider in first approximation that two different kinds of $\mathrm{MgO}$ coexist: (i) one from our target noted $\mathrm{MgO}$, close to stochiometric and characterized by a relatively high barrier height $\Phi_{1}$ and (ii) another created from oxygen diffusion from the first type of $\mathrm{MgO}$ to the $\mathrm{Mg}$ layer noted $\mathrm{MgO}_{x}$ with a lower barrier height $\Phi_{2}$. If $t_{1}$ and $t_{2}$ are the respective thickness of these two oxides then, we have $t_{\mathrm{MgO}}+0.3 \mathrm{~nm}=t_{1}+t_{2}$. For a top insertion, this mechanism of oxygen migration is similar. As predicted from Schrödinger equation, the RA product depends exponentially on the barrier thickness $t$ and the barrier potential height $\Phi$

$$
\mathrm{RA} \propto \exp \left[\frac{4 \pi t \sqrt{2 m} \sqrt{\Phi}}{h}\right],
$$

where $h$ denotes Planck constant and $m$ the electron effective mass. Considering the two types of oxide, we can write:

$$
\begin{aligned}
\mathrm{RA} \propto & \exp \left[\frac{4 \pi \sqrt{2 m} \sqrt{\Phi_{1}}\left(t_{\mathrm{MgO}}+0.3-t_{2}\right)}{h}\right] \\
& \times \exp \left[\frac{4 \pi \sqrt{2 m} \sqrt{\Phi_{2}} t_{2}}{h}\right] .
\end{aligned}
$$

When varying the nominal $\mathrm{MgO}$ thickness, we suppose that $t_{2}$ is not modified. Thus, the $\ln (\mathrm{RA})$ versus $t_{\mathrm{MgO}}$ curve has a slope of $4 \pi\left(2 \mathrm{~m} \Phi_{1}\right)^{1 / 2} / h$ and a shift in $x$-direction given by

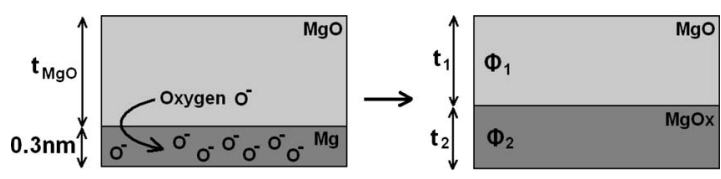

FIG. 3. Schematic of oxygen migration from $\mathrm{MgO}$ layer to $\mathrm{Mg}$ layer in a bottom insertion. 


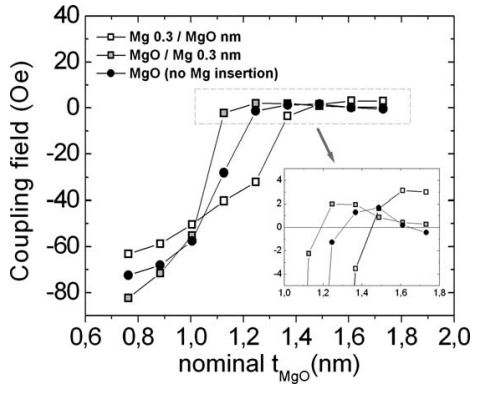

FIG. 4. Coupling field of the free layer plotted as a function of the nominal $\mathrm{MgO}$ thickness.

$$
\frac{4 \pi \sqrt{2 m} \sqrt{\Phi_{1}} 0.3}{h}+\frac{4 \pi \sqrt{2 m}\left(\sqrt{\Phi_{2}}-\sqrt{\Phi_{1}}\right) t_{2}}{h} .
$$

The first term in this expression is positive while the second one is negative since $\Phi_{1}>\Phi_{2}$. Considering that the potential height $\Phi_{1}$ is not modified, the shift can be positive or negative depending on the potential height $\Phi_{2}$ and the thickness $t_{2}$. By assuming that the mechanisms of oxygen migration to the $\mathrm{Mg}$ layer for top and bottom insertion are different, the potential heights in these two configurations are probably different as well as the thickness of the resulting $\mathrm{MgO}_{x}$ layer. This can explain the different shifts in our curves. The slope is about twice larger compared to other measurements in $\mathrm{rf}$ deposited $\mathrm{MgO}^{3}$ It is probably due to crystalline defects in our barrier disfavoring the penetration of electrons with $\Delta_{1}$ symmetry in the barrier. This is consistent with the lower TMR of these samples compared to the literature.

The magnetic hysteresis loop of the free layer was measured by VSM. The loops are slightly shifted from zero field because of the coupling between free layer and pinned layer. This coupling is due to pinholes or orange peel coupling. In the case of direct pinhole coupling, there is an associated decrease in the TMR since the two electrodes cannot be aligned antiparallel. The barrier continuity can be inferred from the free layer coupling field. The coupling field is plotted in Fig. 4 as a function of the MgO thickness for samples with and without $\mathrm{Mg}$ insertions. The coupling changes from antiferromagnetic (positive values) to ferromagnetic as the
$\mathrm{MgO}$ thickness decreases. The inset shows that above a critical thickness, the magnitude of the coupling remains below -4 Oe. For thickness lower than this critical value, the free and pinned layers become increasingly coupled. These critical thicknesses correspond to $1.25,1.36$, and $1.12 \mathrm{~nm}$ for $\mathrm{MgO}$ with no insertion, with a bottom insertion and a top insertion, respectively. The RA measured by TMR CIP measurements for these critical thicknesses are, respectively, 14.6 $\Omega \mu \mathrm{m}^{2}, 13.7 \Omega \mu \mathrm{m}^{2}$, and $10.6 \Omega \mu \mathrm{m}^{2}$. It is interesting to note that these values are remarkably close.

\section{CONCLUSION}

$\mathrm{MgO}$ tunnel barriers were investigated with top and bottom metallic $\mathrm{Mg}$ insertions in the RA range from 1 to $1000 \Omega \mu \mathrm{m}^{2}$. For RA levels larger than $5 \Omega \mu \mathrm{m}^{2}$, the same level of TMR was obtained for the samples with bottom $\mathrm{Mg}$ insertion and without $\mathrm{Mg}$ insertion. In this region, top $\mathrm{Mg}$ insertion samples show lower TMR values decreasing as the metallic $\mathrm{Mg}$ is increased. For RA lower than $5 \Omega \mu \mathrm{m}^{2}$, the TMR is improved and no significant difference is observed on the TMR depending on the location of the $\mathrm{Mg}$ insertion above or below the barrier. In the low RA region, the highest TMR of $50 \%$ at $4.8 \Omega \mu \mathrm{m}^{2}$ was obtained for simultaneous $0.3 \mathrm{~nm}$ thick $\mathrm{Mg}$ insertions below and above the $\mathrm{MgO}$ barrier.

\section{ACKNOWLEDGMENTS}

This work was partially funded by the ANR-07-NANO052-02 project. M. M. C. Souza acknowledges a PhD scholarship funding by Cluster Recherche Micro-Nano and the Rhone-Alpes region.

${ }^{1}$ W. H. Butler, X.-G. Zhang, and T. C. Schulthess, Phys. Rev. B 63, 054416 (2001).

${ }^{2}$ J. Mathon and A. Umerski, Phys. Rev. B 63, 220403(R) (2001).

${ }^{3}$ K. Tsunekawa, D.-D. Djayaprawira, M. Nagai, H. Maehara, S. Yamagata, N. Watanabe, S. Yuasa, Y. Suzuki, and K. Ando, Appl. Phys. Lett. 87, 072503 (2005).

${ }^{4}$ Y. Lu, C. Deranlot, A. Vaurès, F. Petroff, J.-M. George, Y. Zheng, and D. Demailles, Appl. Phys. Lett. 91, 222504 (2007).

${ }^{5}$ D. C. Worledge and P. L. Trouilloud, Appl. Phys. Lett. 83, 84 (2003). 